\title{
Psychological Well-Being and Social Competence During Adolescence: Longitudinal Association Between the Two Phenomena
}

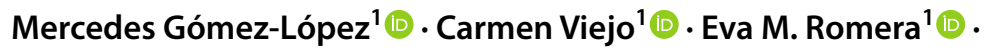 \\ Rosario Ortega-Ruiz ${ }^{1}$ (1)
}

Accepted: 7 December 2021/Published online: 7 January 2022

(c) The Author(s) 2022

\begin{abstract}
Despite previous research on adolescence points to an association between social competence and well-being, limited knowledge is available. Most studies have documented a one-way pattern of influence, although reciprocity has also been suggested. However, they mainly use a cross-sectional design, do not focus on psychological well-being, and do not use integrative and multidimensional constructs. From a eudaimonic approach to well-being and situation-specific to social competence, this study aimed to: (1) explore the factorial structure of the dimensions assessed; (2) analyse the longitudinal relationship between psychological well being and social competence during adolescence; and (3) examine psychological well-being and social competence levels and their stability over time. The sample consisted of 662 adolescents aged between 14 and 16 years old (Time $1 M_{\text {age }}=14.63 ; S D=0.64 ; 51 \%$ girls). Structural equation analysis confirmed the existence of second-order factors, showing evidence of a positive and bidirectional relationship between psychological well-being and social competence. Results also revealed medium-high levels in both constructs, which remained stable over time. These findings highlight the importance of promoting both psychological well-being and social competence to achieve successful, healthy development.
\end{abstract}

Keywords Adolescence $\cdot$ Psychological well-being $\cdot$ Social competence $\cdot$ Secondorder factors $\cdot$ Cross-lagged model $\cdot$ Bidirectional association

Mercedes Gómez-López

mercedes.gomez@uco.es

1 Department of Psychology, University of Cordoba, San Alberto Magno Avenue,

14004 Cordoba, Spain 


\section{Psychological Well-Being and Social Competence During Adolescence}

From a eudaimonic perspective, well-being is not thought of as a final state or outcome, but rather a process of fulfilling human potential. Complementing the hedonic view and adopting a theory-guided approach (Jayawickreme \& DahillBrown, 2016), aspects such as the development of capacities and virtues (Deci \& Ryan, 2008), the attainment of goals and aspirations, and living a life of meaning and purpose (Maddux, 2018) are key concepts in eudaimonic well-being. This viewpoint has led to the consideration of the following interrelated dimensions which, together, make up a global measure of what it means to be "healthy, well, and fully functioning", also known as psychological well-being -PWB- (Ryff \& Singer, 2008, p. 19): self-acceptance, or the ability to recognize multiple aspects of self, including good and bad qualities, and have a positive attitude towards them; positive relations with others, defined as establishing satisfying, close and trusting relationships, characterized by empathy, affection and intimacy; personal growth, which refers to the feeling of being in a state of continuous development, perceiving oneself growing and expanding, and being open to new experiences; purpose in life, or setting goals which give life meaning and direction; environmental mastery, or the ability to efficiently manage the environment and make effective use of the surrounding opportunities; and autonomy, or the ability to regulate behaviour from within, resist social pressure to think or act in a certain ways, and evaluate self by personal standards (Ryff, 2014).

Longitudinal research in adult populations has shown that PWB can act as a protective factor by fostering the building of resources which increase quality of life in the long-term (Huta \& Ryan, 2010; Steger, 2016). Cross-sectional studies carried out in younger samples have drawn similar conclusions, associating PWB with low levels of negative affect and high levels of positive affect and satisfaction with life (Garcia \& Moradi, 2013), as well as finding evidence that high levels of PWB can lead to remembering more positive than negative life events (Garcia \& Siddiqui, 2009), perceiving life as more balanced and harmonious (Garcia et al., 2014), and showing greater resilience in the face of adversity (Sagone \& Caroli, 2014). These findings suggest that dimensions of PWB represent important aspects relating to adolescents' quality of life (Ruini et al., 2011); however, certain limitations still need to be addressed. On the one hand, research on adolescent PWB is still scarce (Gao \& McLellan, 2018), and there are few longitudinal studies which report on how PWB works during this period. In one study by Visani et al. (2011) with a sample of 568 adolescents, the authors found that PWB levels remained relatively stable over a period of three months. To the best of our knowledge, no other studies have explored Ryff's dimensions of PWB in adolescence over time, although it has been analysed using other approaches. Through variables such as self-control, self-esteem, social involvement, enjoyment of school, academic ambitions and the absence of school burnout or internalizing and externalizing symptoms, studies have found both a tendency to decrease (Meade \& Dowswell, 2016), and to maintain a certain stability 
or even improve over time (Fomina et al., 2020; Virtanen et al., 2019). On the other hand, although the theory underlying PWB highlights the need to take into account contextual or relational variables when it is studied and conceptualized (Ryff \& Singer, 2008), there is little available evidence and what there is differs widely from PWB assumptions. The results so far have reported that trust and support provided by peers can contribute to the improvement of PWB in adolescents, assessed in terms of irritability, sadness and stress, and high levels of happiness, energy and satisfaction with oneself (Almquist et al., 2014; Miething et al., 2017). Other findings point to the importance of establishing a secure bond with peers, which is associated with fewer externalized and internalized problems, higher self-esteem, a better self-concept, and a greater ability to cope with stressful life events (Lucktong et al., 2018; McMahon et al., 2020). Although far removed from the dimensions of $\mathrm{PWB}$, these results offer insights to consider, since they stress not only the importance of having friends during adolescence, but also that these relationships provide a safe, comfortable context. Authors such as Ryff and Singer (2008) have already suggested that PWB is heavily influenced by the environment. Adolescence is a developmental stage in which interpersonal relationships are given greater relevance and importance (Bukowski et al., 2018), and is, therefore, an ideal period to analyse this type of process (Visani et al., 2011). For these reasons, it is reasonable to consider that to maintain satisfying interpersonal relationships which have a positive influence on well-being, it is necessary to have the competence that makes them possible.

From a situation-specific approach, social competence -SC- is defined as efficacy in interpersonal interactions (Dirks et al., 2018; Rose-Krasnor \& Denham, 2009), which emerges from exercising social and emotional skills, and leads to acceptance and social inclusion (Gómez-Ortiz et al., 2019). SC develops gradually during childhood and adolescence (Tuerk et al., 2020), although some longitudinal studies have argued that the tendency is for it to show continuity and remain fairly stable during these years (Blair et al., 2015; Bornstein et al., 2013). Over recent decades, the construct of SC has evolved from limited perspectives oriented mainly towards traits or behaviours (Dirks et al., 2018), to more complex, inclusive approaches which acknowledge the existence of the following dimensions (Gómez-Ortiz et al., 2017): prosocial behaviour, or voluntary actions aimed at helping and benefiting others (Eisenberg et al., 2007); cognitive reappraisal, defined as the ability to interpret the meaning of an emotion, regulate it, and modulate one's own coping response to a given situation (Gómez-Ortiz et al., 2017; Opitz et al., 2014); normative adjustment, or the adherence to the norms, conventions and values of social environment (Pozzoli et al., 2012); social adjustment, which refers to the perception of respect, mutual support, belonging to a group and acceptance by others (Rodkin \& Ryan, 2012); and social efficacy, or the patterns of thought and action which lead to consider that a certain social act has succeeded or failed (Rodebaugh, 2006). Taken all together, these elements are essential to capture the multidimensional nature of SC (Gómez-Ortiz et al., 2019), overcome reductionist approaches (Anderson-Butcher et al., 2014), and establish a global construct which includes the personal elements and behavioural dynamics which are needed to meet the demands of each social situation (Dirks et al., 2018). 


\section{Association Between Psychological Well-Being and Social Competence During Adolescence}

There has been little research into the association between PWB and SC during adolescence, and the studies carried out to date have mainly reported on the relationship between specific dimensions or elements of the two phenomena, rather than on their interaction as global or integrative constructs. In general, the specialized literature can be divided into two lines of study: works which analyse these relationships from a one-way angle, and those that do so from a bidirectional approach. The results of the former reveal the predictive role of certain elements of both constructs separately, with most studies focusing on the effects of SC on well-being. Successful interaction with peers has been proposed as a major predictor of mental health during adolescence (Rose-Krasnor \& Denham, 2009), and it has even been suggested that it constitutes one of the main components of healthy functioning and development (Romppanen et al., 2021), and quality of life (Klein \& Englund, 2021). As regards the specific dimensions, prosocial behaviour seems to be a key element for adolescent well-being ( $\mathrm{Li}$ et al., 2021; Son \& Padilla-Walker, 2020), as well as being a driving force of psychological functioning (Demirci, 2020; Hui et al., 2020). Emotional management and regulation have been identified as crucial to ensure positive social development (Gómez-Ortiz et al., 2017; Morrish et al., 2018), and have been found to be positively associated with a meaningful life, flourishing (Garland et al., 2015), self-acceptance, positive relationships, personal growth, purpose in life, environmental mastery and autonomy (Tommasi et al., 2017). Social acceptance and adherence to social rules have been suggested as important indicators of satisfying social relationships and greater self-esteem (Zhang et al., 2014), as well as peer support, which is an important factor in creating a positive self-image (Fernández-Zabala et al., 2020). Finally, adolescents with greater perceived social efficacy and who resort to social support as a coping strategy, show better mental health (Demirci, 2020) and better attitudes towards themselves and towards life (Cicognani, 2011). In addition to these results, the inverse relationship has also been analysed, although to a lesser degree. While no research has been found that specifically addresses the predictive effect of PWB on SC, the available data generally point to the role of well-being as a promoter of positive social outcomes during adolescence. In a meta-analysis carried out by Davis and Suveg (2013), the authors concluded that positive affect in adolescents can not only contribute to psychosocial adjustment, but also even act as a protective factor against adjustment problems or psychopathology. Shin et al. (2011) found that the expression of positive affect predicted peer acceptance and greater initiation of positive interactions, and Agbaria (2020) showed that adolescents with a high level of satisfaction with life were more capable of establishing meaningful friendships, giving help, understanding and cooperating with other people, and resolving conflicts more efficiently. In particular, other studies have shown that high levels of positive affect and low levels of negative affect predict high levels of prosocial behaviour, although they also established that this relationship can be bidirectional (Armstrong-Carter et al., 2020; Chen et al., 2020). 
As regards this bidirectionality and focusing on the second group of studies referred to, the picture is very similar. Research carried out to date does not include a specific analysis of PWB, but it does reveal a reciprocal influence between certain elements of well-being and social competence based on other approaches. Understood in terms of perceived happiness, self-esteem, school burnout or depressive symptoms, well-being seems to promote, and be promoted by factors such as prosocial behaviour and cooperation skills (Backman, 2016; Holopainen et al., 2012). Dealing with more general criteria, a review by Ramsey and Gentzler (2015) reported a consistent bidirectional association between positive affect and positive close relationships throughout the life span, and concluded that there was enough evidence to support a reciprocal relationship between them.

To sum up, research so far has revealed a relationship between well-being and social competence focusing on specific aspects, without delving into their reciprocity or approaching them from a multidimensional and integrative perspective. Therefore, it has not yet been clarified the path or mutuality of these influences, or their evolution throughout the socialization process during adolescence. Moreover, although it appears to be a key factor, there are gaps in the field of psychological well-being which paint a confusing picture that does not allow for solid, reliable conclusions.

\section{The Current Study}

This study is grounded in the theories about well-being and social competence taken from a multidimensional viewpoint (Dirks et al., 2018; Rose-Krasnor \& Denham, 2009; Ryff, 2014). Based on a one-way perspective, most previous studies have pointed to the predictive role of certain elements related to social competence and well-being separately, although from a bidirectional approach, reciprocity has also been suggested. However, there is no research, to our knowledge, which analyses psychological well-being and social competence as second-order constructs encompassing the dimensions detailed above (Gómez-Ortiz et al., 2017; Viejo et al., 2018), or which address the relationship between these constructs and their evolution during adolescence. To address these gaps, the current study had the following aims and hypotheses:

Aim 1: To explore the factorial structure of the dimensions assessed.

H1: The dimensions assessed will comprise second-order factors, depicting PWB and SC constructs.

Aim 2: To analyse the longitudinal relationship between PWB and SC during adolescence.

H2: PWB and SC will show a positive and reciprocal influence over time.

Aim 3: To examine PWB and SC levels and their stability over time.

H3: PWB and SC will remain stable, finding similar levels at both measurement times. 


\section{Method}

\subsection{Participants and Procedure}

An incidental sample was used for this study. At time 1, the sample consisted of 662 adolescents (49\% boys, 51\% girls) aged between 14 and 16 years old $\left(M_{\text {age }}=14.63\right.$, $S D=0.64)$ who attended public and private schools in the Autonomous Community of Andalusia (Spain) $\left(\mathrm{N}_{\text {time } 2}=660\right.$; age range $=14-17$ years, $M_{\text {age }}=15.17$, $S D=0.76$ ). The study was carried out following the guidelines by the Declaration of Helsinki and the Spanish Society of Psychology. Ethical approval was provided by the research ethics committee of the corresponding author's institution. Prior to data collection, authorization was obtained from each school, and informed consent was acquired from the participants' parents or legal guardians. The questionnaire was administered during school hours and filled in individually by each participant. Data collection was performed in two stages, six months apart (October 2017-May 2018). The students were informed that their participation would be voluntary, confidential and anonymous. The average time required to complete the questionnaires was around $20 \mathrm{~min}$. This process was carried out by specialized personnel who did not belong to the schools, following a strict procedure in the collection and processing of the data.

\subsection{Measures}

\subsubsection{Psychological Well-Being}

Psychological well-being was measured using the Brief Scale of Psychological WellBeing for Adolescents (BSPWB-A) (Viejo et al., 2018). This instrument consists of an adaptation for adolescents of the psychological well-being scales developed by Ryff (2014), validated in Spanish. It includes 20 items assessed on a 6-point Likert scale $(1=$ completely disagree; $6=$ completely agree), measuring the degree of agreement with a range of questions relating to the following four dimensions: selfacceptance (e.g. In general, I feel confident and positive about myself) $(\alpha=0.84)$, positive interpersonal relationships (e.g. I know that I can trust my friends, and they know they can trust me) $(\alpha=0.70)$; autonomy (e.g. I often change my mind about decisions if my friends or family disagree) $(\alpha=0.79)$; and life development (e.g. I think everything we experience is an opportunity to grow and to become a better person) $(\alpha=0.80)$.

\subsubsection{Social Competence}

Social competence was assessed using the Adolescent Multidimensional Social Competence Questionnaire (AMSC-Q) (Gómez-Ortiz et al., 2017). This instrument has 26 items, answered using a 7-point Likert scale ( $1=$ completely false; $7=$ completely true) and evaluating five dimensions: prosocial behaviour (e.g. When a classmate or friend 
is sad, I console him/her to make them feel better) $(\alpha=0.78)$, social efficacy (e.g. In relationships with friends and classmates, I feel that I do things well: I feel effective) $(\alpha=0.82)$, social adjustment (e.g. My classmates and friends come to me when they have a problem $)(\alpha=0.90)$, normative adjustment (e.g. I respect other people's opinions even if I don't share them) $(\alpha=0.82)$ and cognitive reappraisal (e.g. When faced with a stressful situation, I try to think about it in a way that helps me to keep calm) $(\alpha=0.84)$.

\subsection{Statistical Analyses}

The descriptive, internal consistency, correlation, and effect size analyses were carried out using SPSS 27.0 statistical software. The effect size was interpreted following the recommendations by Cohen (1988), who established three cut-off points $(0.20=$ small, $0.50=$ medium, $0.80=$ large). The longitudinal relationship between PWB and SC was examined using structural equation analysis (SEM), with EQS 6.2 software. Following the recommendations by Springer and Hauser (2006), the items of the PWB instrument were identified as categorical, so that a more precise estimation of the model could be obtained. Given the nature of the variables and the absence of normality, the Least Squares (LS) estimation method with robust correction was used (Bryant \& Satorra, 2012). To evaluate the model, the Satorra-Bentler parameters were employed, corrected by a robust covariance matrix, as these have been proven to provide the best fit indices in cases of non-normality (Bentler, 2006). In addition to the Satorra-Bentler Chi Square, other fit indices used were the CFI (Comparative Fix Index), NNFI (Non-Normality Fix Index) ( $\geq 0.90$ adequate, $\geq 0.95$ optimal) and RMSEA (Root Mean Square Error of Approximation) ( $\leq 0.08$ adequate, $\leq 0.05$ optimal) (Hu \& Bentler, 1999). The results were also interpreted using $\mathrm{R}^{2}$ (0.01-0.059=small, 0.06-0.139=moderate, $\geq 0.14=$ large) (Cohen, 1988). Finally, since missing data or attrition can lead to a bias in the estimated parameters, Little's MCAR test was performed, which classifies the missing observations into "missing completely at random" (MCAR), "missing at random" (MAR), or "missing not at random" (MNAR) (Little \& Rubin, 2020).

\section{Results}

\subsection{Attrition Analyses}

Little's MCAR test showed a non-significant chi-square at time $1\left(\chi^{2}=0.23\right.$ (1), $p=0.63)$, and similar results were obtained at time $2\left(\chi^{2}=3.88(2), p=0.14\right)$. These data confirm the completely random nature of the missing data (MCAR), and it was therefore decided not to exclude them from the analyses.

\subsection{Preliminary Analyses}

To examine the levels of both PWB and SC, and the suitability of performing more robust analyses (SEM) to explore the factorial structure and the relationship 
Table 1 Descriptive statistics of PWB and SC dimensions at both measurement times

\begin{tabular}{|c|c|c|c|}
\hline & & $\begin{array}{l}\text { Time } 1 \\
\text { Mean }(S D)\end{array}$ & $\begin{array}{l}\text { Time } 2 \\
\text { Mean }(S D)\end{array}$ \\
\hline \multirow{4}{*}{$\begin{array}{l}\text { Psychological well- } \\
\text { being (BSPWB-A) }\end{array}$} & Self-acceptance & $4.76(0.89)$ & $4.71(0.99)$ \\
\hline & Positive interpersonal relationships & $4.71(0.95)$ & $4.78(1.01)$ \\
\hline & Autonomy & $4.03(1.07)$ & $4.09(1.07)$ \\
\hline & Life development & $4.87(0.95)$ & $4.87(0.96)$ \\
\hline \multirow{5}{*}{$\begin{array}{l}\text { Social competence } \\
\text { (AMSC-Q) }\end{array}$} & Prosocial behaviour & $5.35(0.99)$ & $5.24(1.06)$ \\
\hline & Social efficacy & $5.28(1.05)$ & $5.17(1.10)$ \\
\hline & Social adjustment & $5.33(0.99)$ & $5.40(1.04)$ \\
\hline & Normative adjustment & $5.47(1.07)$ & $5.32(1.13)$ \\
\hline & Cognitive reappraisal & $4.89(1.27)$ & $4.87(1.29)$ \\
\hline
\end{tabular}

Missing data ranged from $0.8 \%(n=5)$ to $5.6 \%(n=37)$ across all variables

Table 2 Descriptive statistics, Cronbach's Alpha, paired sample correlations and Cohen's d between second-order variables at both measurement times

\begin{tabular}{|c|c|c|c|c|c|c|c|c|c|}
\hline & \multirow[b]{2}{*}{$M$} & \multirow[b]{2}{*}{$S D$} & \multirow[b]{2}{*}{$\alpha$} & \multicolumn{2}{|l|}{1} & \multicolumn{2}{|l|}{2} & \multicolumn{2}{|l|}{3} \\
\hline & & & & $r$ & $d$ & $r$ & $d$ & $r$ & $d$ \\
\hline 1. PWB (T1) & 4.59 & 0.65 & .84 & - & & & & & \\
\hline 2. PWB (T2) & 4.61 & 0.70 & .86 & $.54 *$ & 0.65 & - & & & \\
\hline 3. SC (T1) & 5.26 & 0.77 & .91 & $.47^{*}$ & 0.74 & $.32 *$ & 0.85 & - & \\
\hline 4. $\mathrm{SC}(\mathrm{T} 2)$ & 5.20 & 0.82 & .92 & $.33^{*}$ & 0.87 & $.50^{*}$ & 0.77 & $.55^{*}$ & 0.76 \\
\hline
\end{tabular}

T1 Time 1; T2 Time 2; * $p=.000$

between the variables, a set of preliminary analyses was carried out. First, means and standard deviations of the dimensions considered were analysed (Table 1). The scores obtained by the participants were medium-high for all the dimensions and at both measurement times.

It was also decided at this preliminary stage to perform descriptive, paired samples correlations and effect size analyses, using variables that grouped together the corresponding dimensions to check their behaviour before performing the SEM analyses (Table 2). The means showed medium-high scores for both PWB and SC at both measurement times, and they were positively and significantly correlated, both cross-sectionally and longitudinally (values between 0.32 and 0.54). Finally, the effect size analyses showed values between 0.65 and 0.87 , which can be considered medium-high.

As the last step in this stage, it was verified whether the variables could be grouped into higher order factors, in order to establish more explanatory and parsimonious model. Following the recommendations by Byrne (2005), correlations between the dimensions of each of the constructs at both measurement times were analysed separately, since second-order structures are viable only if there is 
evidence that the lower order factors are correlated. Results revealed that all the dimensions of the same construct and at the same time showed a positive, significant correlation with each other (values between 0.12 and 0.57 ), although they did not overlap (Table 3).

\subsection{Longitudinal Association Between PWB and SC}

After analysing the preliminary results, it was considered feasible to perform structural equation analysis (SEM) in order to obtain more precise and robust data about the relationship between PWB and SC. A Mardia coefficient of 1123.4184 indicated that the data did not meet the multivariate assumption of normality. The results obtained confirmed the existence of second order-factors that encompassed the dimensions assessed (i.e. PWB and SC), and revealed a cross-lagged model in which PWB turned out to be a reliable predictor of SC, as well as SC of PWB (Fig. 1), showing suitable fit indices: $\chi^{2} \mathrm{~S}-\mathrm{B}=6273.1693 ; \mathrm{df}=4072 ; p<0.000$; $\mathrm{NNFI}=0.984 ; \mathrm{CFI}=0.984$; RMSEA $=0.014$ [90\% CI $(0.011,0.017)$ ]. As regards the magnitude of the relationships found, Table 4 shows the standardized solution for first and second order factors. The explained variance $\left(\mathrm{R}^{2}\right)$ ranged from 28 to $84 \%$, which were high values in all cases, especially in the causal relationships

Table 3 Bivariate correlations between PWB and SC dimensions at both measurement times

\begin{tabular}{|c|c|c|c|c|c|c|}
\hline & & 1 & 2 & 3 & 4 & 5 \\
\hline \multirow[t]{4}{*}{ PWB (T1) } & 1. SA & - & & & & \\
\hline & 2. PIR & $.36^{*}$ & - & & & \\
\hline & 3. AUT & $.39 *$ & $.33^{*}$ & - & & \\
\hline & 4. LD & $.39 *$ & $.33^{*}$ & $.12 *$ & - & \\
\hline \multirow[t]{4}{*}{ PWB (T2) } & 1. SA & - & & & & \\
\hline & 2. PIR & $.35^{*}$ & - & & & \\
\hline & 3. AUT & $.43^{*}$ & $.39 *$ & - & & \\
\hline & 4. LD & $.45^{*}$ & $.32^{*}$ & $.18^{*}$ & - & \\
\hline \multirow[t]{5}{*}{$\mathrm{SC}$ (T1) } & 1. $\mathrm{PB}$ & - & & & & \\
\hline & 2. SE & $.39 *$ & - & & & \\
\hline & 3. SAD & $.47^{*}$ & $.55^{*}$ & - & & \\
\hline & 4. NAD & $.34^{*}$ & $.48^{*}$ & $.32 *$ & - & \\
\hline & 5. CR & $.30^{*}$ & $.32 *$ & $.30 *$ & $.45^{*}$ & - \\
\hline \multirow[t]{5}{*}{$\mathrm{SC}(\mathrm{T} 2)$} & 1. $\mathrm{PB}$ & - & & & & \\
\hline & 2. $\mathrm{SE}$ & $.40^{*}$ & - & & & \\
\hline & 3. SAD & $.53 *$ & $.57 *$ & - & & \\
\hline & 4. NAD & $.38^{*}$ & $.47 *$ & $.37 *$ & - & \\
\hline & 5. CR & $.34 *$ & $.36^{*}$ & $.37 *$ & $.48 *$ & - \\
\hline
\end{tabular}

$T 1$ Time 1; T2 Time 2; SA Self-Acceptance; PIR Positive Interpersonal Relationships; $A U T$ Autonomy; $L D$ Life Development; $P B$ Prosocial Behaviour; $S E$ Social Efficacy; $S A D$ Social Adjustment; $N A D$ Normative Adjustment; $C R$ Cognitive Reappraisal; ${ }^{*} p=.000$ 


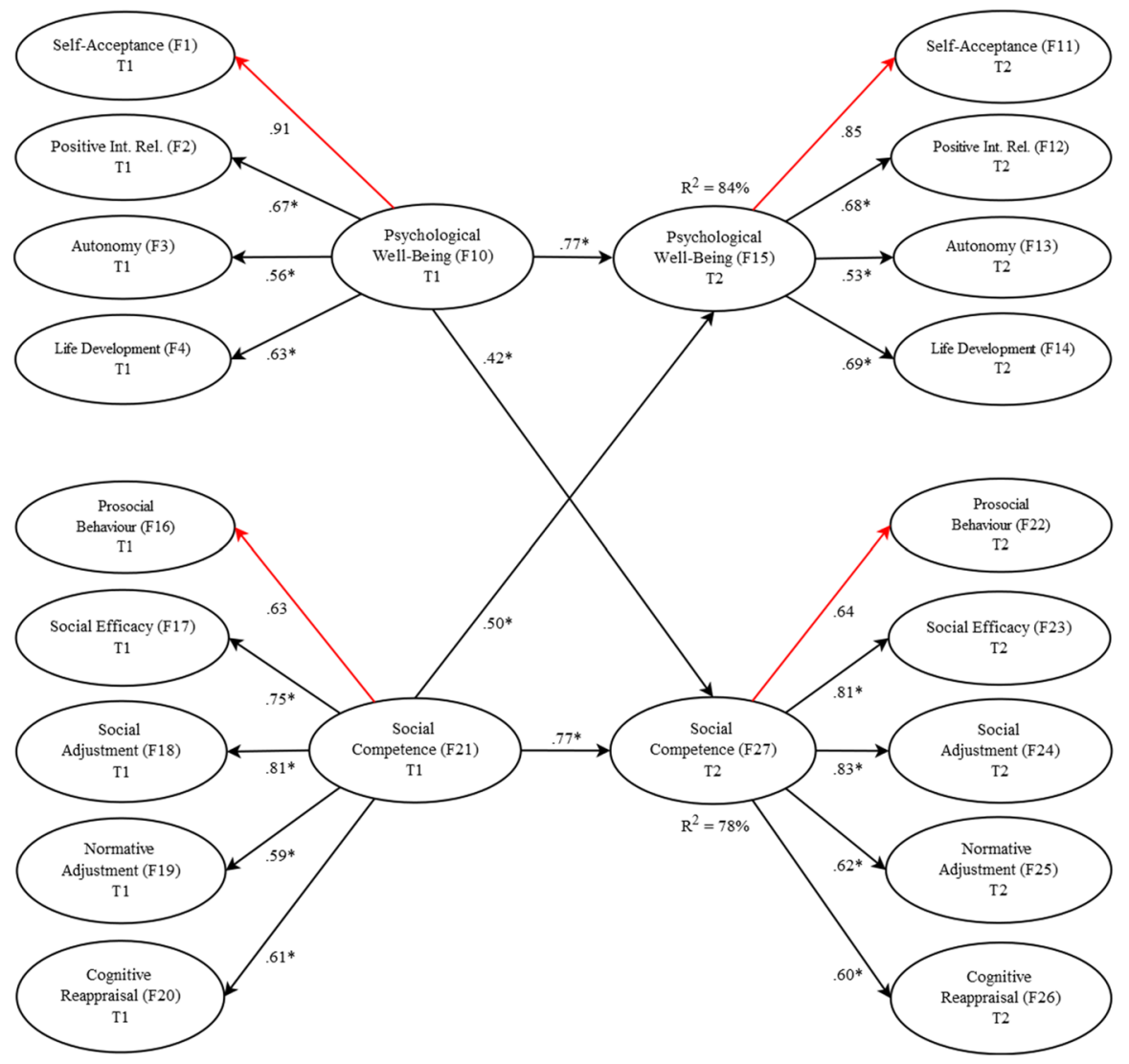

Fig. 1 Cross-lagged model for PWB and SC during adolescence. Notes: T1 Time 1; T2 Time 2; * $p<.05$

between PWB and SC (Fig. 1). In addition, the SEM analysis revealed a positive and significant influence between both measurement times in relation to both PWB $(\beta=0.77 ; p<0.05)$ and $\mathrm{SC}(\beta=0.77 ; p<0.05)$ (Fig. 1$)$. Therefore, taking into account the mean scores obtained by the participants in both factors (Table 2), it can be considered that constructs remain stable, despite the slight increase in PWB and the small decrease in SC in wave 2.

\section{Discussion}

This work explores further the association between psychological well-being (PWB) and social competence (SC) during adolescence, using a eudaimonic approach to well-being and situation-specific to social competence (Dirks et al., 2018; GómezOrtiz et al., 2017; Rose-Krasnor \& Denham, 2009; Ryff, 2014; Viejo et al., 2018). Given the gaps in the literature about the relationship between these two phenomena, the limited availability of longitudinal data, and the lack of evidence found on 
Table 4 Least Squares (LS) standardized solution with robust statistics for first and second-order factors

\begin{tabular}{ll}
\hline Standardized solution & R-Squared \\
\hline $\mathrm{F} 1=\mathrm{F} 1=.914 \mathrm{~F} 10+.406 \mathrm{D} 1$ & .835 \\
$\mathrm{~F} 2=\mathrm{F} 2=.674 * \mathrm{~F} 10+.739 \mathrm{D} 2$ & .454 \\
$\mathrm{~F} 3=\mathrm{F} 3=.558 * \mathrm{~F} 10+.830 \mathrm{D} 3$ & .312 \\
$\mathrm{~F} 4=\mathrm{F} 4=.631 * \mathrm{~F} 10+.776 \mathrm{D} 4$ & .399 \\
$\mathrm{~F} 11=\mathrm{F} 11=.850 \mathrm{~F} 15+.527 \mathrm{D} 11$ & .722 \\
$\mathrm{~F} 12=\mathrm{F} 12=.678 * \mathrm{~F} 15+.735 \mathrm{D} 12$ & .460 \\
$\mathrm{~F} 13=\mathrm{F} 13=.530 * \mathrm{~F} 15+.848 \mathrm{D} 13$ & .281 \\
$\mathrm{~F} 14=\mathrm{F} 14=.686 * \mathrm{~F} 15+.728 \mathrm{D} 14$ & .471 \\
$\mathrm{~F} 15=\mathrm{F} 15=.768 * \mathrm{~F} 10+.497 * \mathrm{~F} 21+.404 \mathrm{D} 15$ & .836 \\
$\mathrm{~F} 16=\mathrm{F} 16=.630 \mathrm{~F} 21+.777 \mathrm{D} 16$ & .397 \\
$\mathrm{~F} 17=\mathrm{F} 17=.751 * \mathrm{~F} 21+.660 \mathrm{D} 17$ & .564 \\
$\mathrm{~F} 18=\mathrm{F} 18=.809 * \mathrm{~F} 21+.587 \mathrm{D} 18$ & .655 \\
$\mathrm{~F} 19=\mathrm{F} 19=.595 * \mathrm{~F} 21+.804 \mathrm{D} 19$ & .354 \\
$\mathrm{~F} 20=\mathrm{F} 20=.607 * \mathrm{~F} 21+.795 \mathrm{D} 20$ & .368 \\
$\mathrm{~F} 22=\mathrm{F} 22=.641 \mathrm{~F} 27+.767 \mathrm{D} 22$ & .411 \\
$\mathrm{~F} 23=\mathrm{F} 23=.815 * \mathrm{~F} 27+.580 \mathrm{D} 23$ & .664 \\
$\mathrm{~F} 24=\mathrm{F} 24=.830 * \mathrm{~F} 27+.558 \mathrm{D} 24$ & .688 \\
$\mathrm{~F} 25=\mathrm{F} 25=.616 * \mathrm{~F} 27+.788 \mathrm{D} 25$ & .379 \\
$\mathrm{~F} 26=\mathrm{F} 26=.599 * \mathrm{~F} 27+.800 \mathrm{D} 26$ & .359 \\
$\mathrm{~F} 27=\mathrm{F} 27=.421 * \mathrm{~F} 10+.774 * \mathrm{~F} 21+.473 \mathrm{D} 27$ & .776 \\
\hline
\end{tabular}

$F$ Factor, $D$ Residual error

PWB, this study had the following aims: (1) to explore the factorial structure of the dimensions assessed; (2) to analyse the longitudinal relationship between PWB and SC during adolescence; and (3) to examine PWB and SC levels and their stability over time.

\subsection{Psychological Well-Being and Social Competence: a Two-Way Pattern of Influence}

In line with Hypothesis 1, the results showed second-order factor structures that integrated the dimensions assessed in two global constructs: psychological wellbeing and social competence. The confirmation of higher order structures makes it possible to go beyond the data using first-order factors to explain the association between the two phenomena (Backman, 2016; Chen et al., 2020; Holopainen et al., 2012), as well as to present a more accurate and explanatory model of the relationships described: this is the first study, as far as we know, to use this procedure and this theoretical approach with these constructs. The model presented offers several advantages compared to first-order ones, such as the possibility of explaining the covariance between lower-order factors in a more accurate way with fewer parameters, or providing a useful simplification of how to interpret complex measurement structures (Chen et al., 2009). In this sense and confirming the Hypothesis 2, 
a positive and bidirectional relationship was found between both constructs. That is, the data suggest a simultaneous relationship between PWB and SC over time. Correlation and effect size analysis already suggested this interdependence both crosssectionally and longitudinally, the latter being confirmed by SEM analyses. It is possible that the six-month period between the two waves is short enough to capture this simultaneity for time 2 , but also that it is the result of a joint functioning of both constructs at time 1 . In other words, the data could be pointing to PWB and SC nurturing each other, and that relationship being maintained over time. This could mean that interdependence between the two phenomena is an important factor to take into account, highlighting that promoting both together could lead to more beneficial outcomes than doing so independently. More specifically, these considerations are also supported by the results showing that PWB predicts an increase in SC, just as SC predicts an increase in PWB, suggesting this that adolescents need to be socially competent to experience high levels of psychological well-being, but they also need to experience high levels of psychological well-being to be socially competent, which is consistent with the notion that psychological well-being and social environment are closely related (Ryff \& Singer, 2008). From this angle, it makes sense to assume that being "healthy, well, and fully functioning" (i.e. PWB, Ryff \& Singer, 2008 , p. 19) leads to being more effective in social interactions, and that this effectiveness results in higher levels of psychological well-being during adolescence.

The two-way pattern of influence found between PWB and SC also extends the data reported by one-way studies, as well as the trend suggested by works using a bidirectional approach, thus providing a broader framework trough which to understand the relationship between the two constructs. In this field, research has reported separately the influence of certain elements of social competence on well-being and vice versa. Examples of this are provided by the results showing the influence on positive functioning, flourishing, mental health, self-esteem, or Ryff's PWB dimensions of factors such as social skills (Romppanen et al., 2021), prosociality (Demirci, 2020; Hui et al., 2020; Li et al., 2021; Son \& PadillaWalker, 2020), the ability to manage emotions (Garland et al., 2015; Tommasi et al., 2017), social acceptance and adherence to social rules (Tommasi et al., 2017; Zhang et al., 2014), perceived peer support (Fernández-Zabala et al., 2020), or perceived social efficacy (Cicognani, 2011; Demirci, 2020). To this overview should be added those studies which have suggested that aspects related to wellbeing, such as satisfaction with life, positive affect, high self-esteem or low levels of school burnout and depressive symptoms, can contribute to psychosocial adjustment, fostering the establishment of more meaningful bonds, an improvement in cooperation skills (Agbaria, 2020; Backman, 2016; Holopainen et al., 2012), and better social interactions (Shin et al., 2011), characterized by empathy, prosocial behaviour, understanding, cooperation or better conflict resolution, thus acting as a protective factor against adjustment problems or psychopathology (Davis \& Suveg, 2013). Other authors have also highlighted this protective role of PWB, finding it associated with aspects such as high levels of positive affect and satisfaction with life (Garcia \& Moradi, 2013), remembering more positive life events than negative ones (Garcia \& Siddiqui, 2009), the perception of life 
as balanced and harmonious (Garcia et al., 2014), and a high level of resilience (Sagone \& Caroli, 2014).

The results obtained are also in line with studies pointing to the reciprocity between well-being and social competence (Armstrong-Carter et al., 2020; Backman, 2016; Chen et al., 2020; Holopainen et al., 2012; Ramsey \& Gentzler, 2015), but going a step further: by using theoretical approaches congruent with the construct measured, and analysing specific dimensions of both PWB and SC, it is possible to present a more accurate picture of the mutuality between two phenomena that, being so closely related to adolescents' quality of life (Klein \& Englund, 2021; Ruini et al., 2011), have not received due attention.

Finally, in line with the approaches which focus on the strengths and capacity of adolescents to achieve a successful adjustment (Oliva et al., 2017), these findings highlight the benefits that promoting well-being can accrue to the achievement of a flourishing, socially successful adolescence. Therefore, the contribution to PWB made by this work is of particular use, since, to the best of our knowledge, no studies to date have linked it to SC from a eudaimonic perspective. The study of PWB in stages prior to adulthood is a field which has been largely neglected (Ben-Arieh et al., 2014; Gao \& McLellan, 2018), which has led to a significant gap in knowledge that prevents from obtaining an in-depth understanding of its potentialities. From this approach, well-being is not understood as a result or final state, but rather as a process of realizing one's own potential, flourishing, acquiring skills and making continuous improvement (Deci \& Ryan, 2008). It is particularly coherent to adopt this perspective towards the study of well-being during adolescence, since it captures its essence as a period marked by development, change and growth (Steinberg, 2016). Fostering psychological well-being can offer adolescents greater opportunities for self-realization and optimal functioning, by helping them to recognize their strengths, learn from their weaknesses, and attain the best version of themselves (Visani et al., 2014). Similarly, the results obtained reinforce the view of interpersonal relationships as a key element during adolescence which is strongly linked to well-being, although from a less well-analysed perspective: the fact that it is important for adolescents to be able to ensure that these relationships provide them with a safe and comfortable context, bearing in mind that they will have to know how to adapt their skills to the situation in which they are involved (Dirks et al., 2018).

\subsection{Stability of Psychological Well-Being and Social Competence Over Time}

The third aim of this work was to analyse PWB and SC levels and their stability over time. The results revealed there was a slight increase in PWB and a small decrease in $\mathrm{SC}$ in time 2. However, the changes represent minor differences with respect to time 1. Therefore, these data can be considered as confirming Hypothesis 3, and suggest an opposite trend to the results showing a decrease in well-being over time (Meade \& Dowswell, 2016), being in line with those studies which have reported certain stability or improvement (Fomina et al., 2020; Virtanen et al., 2019; Visani et al., 2011). In addition, they are consistent with the notion that SC tends to remain stable during adolescence (Blair et al., 2015; Bornstein et al., 2013). This may be related to 
studies which have documented the stability of eudaimonic well-being, stating that activities consistent with it, such as cultivating healthy, trust-based relationships, or striving to become an autonomous, competent person, foster the building of lasting resources which are beneficial for long-term adjustment and quality of life (Huta \& Ryan, 2010; Steger, 2016). However, these results must be interpreted with caution, due, firstly, to the short length of time between the two waves, and, secondly, to the added difficulty that there are limited research focused on adolescence using these theoretical assumptions, especially in relation to PWB.

Furthermore, the data revealed medium-high levels of both PWB and SC, which means that participants showed a positive attitude towards themselves, accepting both their good and bad qualities (self-acceptance), felt that they were improving over time and developing their potential (life development), were capable of maintaining relationships based on trust, intimacy, and empathy (positive interpersonal relationships), and were self-determined and independent (autonomy). Moreover, they reported they were able to interpret and regulate their emotions (cognitive reappraisal), act voluntarily to promote the well-being of others (prosocial behaviour) and adjust and follow the norms and conventions of their social environment (normative adjustment), while perceiving themselves as effective in different social settings (social efficacy) and feeling accepted and valued by their peers (social adjustment). These data pointed to the usefulness of these two constructs as reliable predictors of themselves, and display a portrayal of adolescence which differs from the widespread conceptualization of it being a particularly problematic period marked by instability and conflict. Likewise, they are in line with the approaches that advocate the need to focus not only on negative outcomes during adolescence and how to prevent them, but also on its positive features and the promotion of well-being and competence as central aspects of positive development, stating that "every adolescent has the potential for successful and healthy development" (Oliva et al., 2017, p. 16).

\section{Conclusions and Practical Implications}

The results of this work contribute to extending the knowledge about positive functioning during adolescence, by pointing to a close relationship between psychological well-being and social competence. In this sense, the data suggest that promoting SC can be an effective tool for achieving good levels of PWB, and that fostering PWB can also bring beneficial outcomes in terms of successful, satisfying interpersonal relationships. Therefore, regarding the practical implications of this research, the results obtained reinforce the importance of designing and carrying out educational initiatives aimed at teaching adolescents to effectively manage their interpersonal relationships, given the benefits that being socially competent can accrue in terms of social adjustment and well-being. It is also essential for these actions to include the promotion of PWB, given the influence it can exert on successful interpersonal development. However, if these types of procedures are to be coherent, they must rely on a balanced conception of adolescence. In other words, they must consider not only the difficulties, but also the potential and ability of adolescents 
to prosper, flourish, and be highly competent in one of the most relevant tasks they have to address during this stage of life: building healthy, positive, and satisfying interpersonal relationships.

\section{Limitations and Future Research}

The present study has certain limitations which must be mentioned. Firstly, the use of self-reports can lead to the participants' responses being influenced by a positivist bias, or a tendency to overestimate the real values of their experiences. Second, although it was a longitudinal study, the follow-up period was short, so longer-term studies may provide more evidence to support, expand, or complete the conclusions reached. In this context, it would be very interesting for future research to explore further the evolution of the relationship found, as well as its possible role as a predictor of other positive outcomes during adolescence. Finally, the confusing scenario found with respect to psychological well-being points to the need to use theoretical approaches congruent with the constructs measured, thus consolidating the understanding of positive development as something more than merely the absence of symptoms, problems or difficulties.

Acknowledgements This publication is supported by the following research projects: "La dimensión moral como clave para la comprensión y prevención del acoso escolar y ciberacoso". Ministerio de Ciencia e Innovación (Ref. PDC2021-121741-I00) and "Proceso psicoevolutivo y educativo del cortejo adolescente: Competencia sentimental y ajuste social". Programa Operativo FEDER Andalucía 20142020 (Ref. UCO-1380774).

Funding Open Access funding provided thanks to the CRUE-CSIC agreement with Springer Nature. For open access charge: Universidad de Córdoba/CBUA

Availability of Data and Material The data of this study is available upon reasonable request.

Code Availability Not applicable.

\section{Declarations}

Ethics Approval The study was carried out following the guidelines by the Declaration of Helsinki and the Spanish Society of Psychology. Ethical approval for the study was provided by the research ethics committee of the corresponding author's institution.

Consent to Participate Authorization was obtained from each school and informed consent was acquired from the participants' parents or legal guardians.

Consent for Publication Not applicable.

Conflicts of Interest The authors declare that they have no conflict of interest.

Open Access This article is licensed under a Creative Commons Attribution 4.0 International License, which permits use, sharing, adaptation, distribution and reproduction in any medium or format, as long as you give appropriate credit to the original author(s) and the source, provide a link to the Creative Commons licence, and indicate if changes were made. The images or other third party material in this article are included in the article's Creative Commons licence, unless indicated otherwise in a credit line to the 
material. If material is not included in the article's Creative Commons licence and your intended use is not permitted by statutory regulation or exceeds the permitted use, you will need to obtain permission directly from the copyright holder. To view a copy of this licence, visit http://creativecommons.org/licen ses/by/4.0/.

\section{References}

Agbaria, Q. (2020). Predictors of personal and social adjustment among Israeli-Palestinian teenagers. Child Indicators Research, 13(3), 917-933. https://doi.org/10.1007/s12187-019-09661-3.

Almquist, Y., Östberg, V., Rostila, M., Edling, C., \& Rydgren, J. (2014). Friendship network characteristics and psychological well-being in late adolescence: Exploring differences by gender and gender composition. Scandinavian Journal of Public Health, 42(2), 146-154. https://doi.org/10.1177/ 1403494813510793.

Anderson-Butcher, D., Amorose, A. J., Lower, L. M., Riley, A., Gibson, A., \& Ruch, D. (2014). The case for the Perceived Social Competence Scale II. Research on Social Work Practice, 26(4), 419-428. https://doi.org/10.1177/1049731514557362.

Armstrong-Carter, E., Guassi-Moreira, J. F., Ivory, S. L., \& Telzer, E. H. (2020). Daily links between helping behaviors and emotional well-being during late adolescence. Journal of Research on Adolescence, 30(4), 1-13. https://doi.org/10.1111/jora.12572.

Backman, Y. (2016). Circles of happiness: Students' perceptions of bidirectional crossovers of subjective well-being. Journal of Happiness Studies, 17, 1547-1563. https://doi.org/10.1007/ s10902-015-9658-0.

Ben-Arieh, A., Casas, F., Frønes, I., \& Korbin, J. E. (2014). Multifaceted concept of child well-being. In A. Ben-Aireh, F. Casas, I. Frønes, \& J. E. Korbin (Eds.), Handbook of child well-being. Theories, methods and policies in global perspective (pp. 1-28). Springer.

Bentler, P. M. (2006). EQS 6 Structural Equations Program Manual. Multivariate Software.

Blair, B. L., Perry, N. B., O’Brien, M., Calkins, S. D., Keane, S. P., \& Shanahan, L. (2015). Identifying developmental cascades among differentiated dimensions of social competence and emotion regulation. Developmental Psychology, 51(8), 1062-1073. https://doi.org/10.1037/a0039472.

Bornstein, M. H., Hahn, C., \& Suwalsky, J. T. D. (2013). Developmental pathways among adaptive functioning and externalizing and internalizing behavioral problems: Cascades from childhood into adolescence. Applied Developmental Science, 17(2), 76-87. https://doi.org/10.1080/10888691.2013. 774875 .

Bryant, F. B., \& Satorra, A. (2012). Principles and practice of scaled difference Chi-Square testing. Structural Equation Modeling, 19(3), 372-398. https://doi.org/10.1080/10705511.2012.687671.

Bukowski, W. M., Laursen, B., \& Rubin, H. (2018). Peer relations: Past, present, and promise. In W. M. Bukowski, B. Laursen, \& H. Rubin (Eds.), Handbook of peer interactions, relationships and groups (2nd ed., pp. 3-20). The Guilford Press.

Byrne, B. M. (2005). Factor analytic models: Viewing the structure of an assessment instrument from three perspectives. Journal of Personality Assessment, 85(1), 17-32. https://doi.org/10.1207/s1532 7752jpa8501_02.

Chen, F. F., Sousa, K. H., \& West, S. G. (2009). Teacher's corner: Testing measurement invariance of second-order. Structural Equation Modeling, 12(3), 471-492. https://doi.org/10.1207/s15328007s em1203_7.

Chen, X., Tian, L., \& Huebner, E. S. (2020). Bidirectional relations between subjective well-being in school and prosocial behavior among elementary school-aged children: A longitudinal study. Child and Youth Care Forum, 49(1), 77-95. https://doi.org/10.1007/s10566-019-09518-4.

Cicognani, E. (2011). Coping strategies with minor stressors in adolescence: Relationships with social support, self-efficacy, and psychological well-being. Journal of Applied Social Psychology, 41(3), 559-578. https://doi.org/10.1111/j.1559-1816.2011.00726.x.

Cohen, J. (1988). Statistical power analysis for the behavioral sciences. Routledge.

Davis, M., \& Suveg, C. (2013). Focusing on the positive: A review of the role of child positive affect in developmental psychopathology. Clinical Child and Family Psychology Review, 17, 97-124. https:// doi.org/10.1007/s10567-013-0162-y. 
Deci, E. L., \& Ryan, R. M. (2008). Hedonia, eudaimonia, and well-being: An introduction. Journal of Happiness Studies, 9, 1-11. https://doi.org/10.1007/s10902-006-9018-1.

Demirci, I. (2020). School engagement and well-being in adolescents: Mediating roles of hope and social competence. Child Indicators Research, 13, 1573-1595. https://doi.org/10.1007/ s12187-020-09722-y.

Dirks, M. A., Kirmayer, M. H., \& Morningstar, M. (2018). Social competence. In R. J. R. Levesque (Ed.), Encyclopedia of adolescence (2nd. ed., pp. 3636-3647). Springer.

Eisenberg, N., Fabes, R. A., \& Spinrad, T. L. (2007). Handbook of child psychology. Wiley.

Fernández-Zabala, A., Ramos-Díaz, E., Rodríguez-Fernández, A., \& Núñez, J. L. (2020). Sociometric popularity, perceived peer support, and self-concept in adolescence. Frontiers in Psychology, 11, Article 594007. https://doi.org/10.3389/fpsyg.2020.594007.

Fomina, T., Burmistrova-Savenkova, A., \& Morosanova, V. (2020). Self-regulation and psychological well-being in early adolescence: A two-wave longitudinal study. Behavioral Sciences, 10(3), 67. https://doi.org/10.3390/bs10030067.

Gao, J., \& McLellan, R. (2018). Using Ryff's scales of psychological well-being in adolescents in mainland China. BMC Psychology, 6, 17. https://doi.org/10.1186/s40359-018-0231-6.

Garcia, D., \& Moradi, S. (2013). The affective temperaments and well-being: Swedish and Iranian adolescents' life satisfaction and psychological well-being. Journal of Happiness Studies, 14(2), 689707. https://doi.org/10.1007/s10902-012-9349-z.

Garcia, D., \& Siddiqui, A. (2009). Adolescents' affective temperaments: Life satisfaction, interpretation, and memory of events. The Journal of Positive Psychology, 4(2), 155-167. https://doi.org/10.1080/ 17439760802399349.

Garcia, D., Al Nima, A., \& Kjell, O. N. E. (2014). The affective profiles, psychological well-being, and harmony: Environmental mastery and self-acceptance predict the sense of a harmonious life. PeerJ, 2, Article e259. https://doi.org/10.7717/peerj.259.

Garland, E., Farb, N. A., Goldin, P. R., \& Fredrickson, B. L. (2015). Mindfulness broadens awareness and builds eudaimonic meaning: A process model of mindful positive emotion regulation. Psychological Inquiry, 26(4), 1532-7965. https://doi.org/10.1080/1047840X.2015.1064294.

Gómez-Ortiz, O., Romera-Félix, E. M., \& Ortega-Ruiz, R. (2017). Multidimensionality of social competence: Measurement of the construct and its relationship with bullying roles. Revista De Psicodidactica, 22(1), 37-44. https://doi.org/10.1387/RevPsicodidact.15702.

Gómez-Ortiz, O., Romera, E. M., Ortega-Ruiz, R., Herrera, M., \& Norman, J. O. (2019). Multidimensional social competence in research on bullying involvement: A cross-cultural study. Behavioral Psycholoy, 27(2), 217-238. Retrieved December 18, 2021 from. https://www.behavioralpsycho. com/wp-content/uploads/2019/10/03.Gomez-Ortiz-27-2oaEn.pdf

Holopainen, L., Lappalainen, K., Junttila, N., \& Savolainen, H. (2012). The role of social competence in the psychological well-being of adolescents in secondary education. Scandinavian Journal of Educational Research, 56(2), 199-212. https://doi.org/10.1080/00313831.2011.581683.

Hu, L., \& Bentler, P. M. (1999). Cutoff criteria for fot indexes in covariance structure analysis: Conventional criteria versus new alternatives. Structural Equation Modeling, 6(1), 1-55. https://doi.org/10. 1080/10705519909540118.

Hui, B. P. H., Ng, J. C. K., Berzaghi, E., Cunningham-Amos, L. A., \& Kogan, A. (2020). Rewards of kindness? A meta-analysis of the link between prosociality and well-being. Psychological Bulletin, 146(12), 1084-1116. https://doi.org/10.1037/bul0000298.

Huta, V., \& Ryan, R. M. (2010). Pursuing pleasure or virtue: The differential and overlapping well-being benefits of hedonic and eudaimonic motives. Journal of Happiness Studies, 11, 735-762. https://doi. org/10.1007/s10902-009-9171-4.

Jayawickreme, E., \& Dahill-Brown, S. E. (2016). Developing well-being and capabilities as a goal of higher education: A thought-piece on educating the whole student. In J. Vitters $\emptyset$ (Ed.), Handbook of eudaimonic well-being (pp. 473-484). Springer.

Klein, R. J., \& Englund, M. M. (2021). Developmental pathways to adult happiness: Social competence and timely high school graduation. Journal of Happiness Studies. https://doi.org/10.1007/ s10902-021-00354-9.

Li, J., Yao, M., \& Liu, H. (2021). From social support to adolescents' subjective well-being: The mediating role of emotion regulation and prosocial behavior and gender difference. Child Indicators Research, 14(1), 77-93. https://doi.org/10.1007/s12187-020-09755-3.

Little, R. J. A., \& Rubin, D. B. (2020). Statistical analysis with missing data (3rd Ed.). Wiley. 
Lucktong, A., Salisbury, T. T., \& Chamratrithirong, A. (2018). The impact of parental, peer and school attachment on the psychological well-being of early adolescents in Thailand. International Journal of Adolescence and Youth, 23(2), 235-249. https://doi.org/10.1080/02673843.2017.1330698.

Maddux, J. E. (2018). Subjective well-being and life satisfaction. An introduction to conceptions, theories, and measures. In J. E. Maddux (Ed.), Subjective well-being and life satisfaction (pp. 3-31). Routledge.

McMahon, G., Creaven, A., \& Gallagher, S. (2020). Stressful life events and adolescent well-being: The role of parent and peer relationships. Stress and Health, 36(3), 299-310. https://doi.org/10.1002/ smi.2923.

Meade, T., \& Dowswell, E. (2016). Adolescents' health-related quality of life (HRQoL) changes over time: A three year longitudinal study. Health and Quality of Life Outcomes, 14, 14. https://doi.org/ 10.1186/s 12955-016-0415-9.

Miething, A., Almquist, Y. B., Edling, C., Rydgren, J., \& Rostila, M. (2017). Friendship trust and psychological well-being from late adolescence to early adulthood: A structural equation modelling approach. Scandinavian Journal of Public Health, 45(3), 244-252. https://doi.org/10.1177/14034 94816680784.

Morrish, L., Rickard, N., Chin, T. C., \& Vella-Brodrick, D. A. (2018). Emotion regulation in adolescent well-being and positive education. Journal of Happiness Studies, 19, 1543-1564. https://doi.org/10. 1007/s10902-017-9881-y.

Oliva, A., Antolín-Suárez, L., Povedano, A., Suárez, C., del Moral, G., Rodríguez-Meirinhos, A., Capecci, V., \& Musitu, G. (2017). Bienestar y desarrollo positivo adolescente desde una perspectiva de género: Un estudio cualitativo. Centro Reina Sofía sobre adolescencia y juventud.

Opitz, P. C., Lee, I. A., Gross, J. J., \& Urry, H. L. (2014). Fluid cognitive ability is a resource for successful emotion regulation in older and younger adults. Frontiers in Psychology, 5, Article 609. https:// doi.org/10.3389/fpsyg.2014.00609.

Pozzoli, T., Gini, G., \& Vieno, A. (2012). The role of individual correlates and class norms in defending and passive bystanding behavior in bullying: A multilevel analysis. Child Development, 38(6), 1917-1931. https://doi.org/10.1111/j.1467-8624.2012.01831.x.

Ramsey, M. A., \& Gentzler, A. L. (2015). An upward spiral: Bidirectional associations between positive affect and positive aspects of close relationships across the life span. Developmental Review, 36, 58-104. https://doi.org/10.1016/j.dr.2015.01.003.

Rodebaugh, T. L. (2006). Self-efficacy and social behavior. Behaviour Research and Therapy, 44(12), 1831-1838. https://doi.org/10.1016/j.brat.2005.11.014.

Rodkin, P. C., \& Ryan, A. M. (2012). Child and adolescent peer relations in educational context. In K. R. Harris, S. Graham \& T. Urdan (Eds.), APA education psychology handbook: Individual differences and cultural and contextual factors (Vol. 2, pp. 363-389). American Psychological Association.

Romppanen, E., Korhonen, M., Salmelin, R. K., Puura, K., \& Luoma, I. (2021). The significance of adolescent social competence for mental health in young adulthood. Mental Health \& Prevention, 21, Article 200198. https://doi.org/10.1016/j.mhp.2021.200198.

Rose-Krasnor, L., \& Denham, S. (2009). Social-emotional competence in early childhood. In K. H. Rubin, W. M. Bukowski, \& B. Laursen (Eds.), Handbook of peer interactions, relationships, and groups (pp. 162-179). Guilford Press.

Ruini, C., Ottolini, F., Tomba, E., Belaise, C., Albieri, E., Visani, D., Caffo, E., \& Fava, A. (2011). School interventions for promoting psychological well-being in adolescence. In I. Brdar (Ed.), The human pursuit of well-being. A cultural approach (pp. 237-246). Springer.

Ryff, C. D. (2014). Psychological well-being revisited: Advances in the science and practice of eudaimonia. Psychotherapy and Psychosomatics, 83(1), 10-28. https://doi.org/10.1159/000353263.

Ryff, C. D., \& Singer, B. H. (2008). Know thyself and become what you are: A eudaimonic approach to psychological well-being. Journal of Happiness Studies, 9, 13-39. https://doi.org/10.1007/ s10902-006-9019-0.

Sagone, E., \& De Caroli, M. E. (2014). Relationships between psychological well-being and resilience in middle and late adolescents. Procedia-Social and Behavioral Sciences, 141, 881-887. https://doi. org/10.1016/j.sbspro.2014.05.154.

Shin, N., Vaughn, B. E., Akers, V., Kim, M., Stevens, S., Krzysik, L., Coppola, G., Bost, K. K., Mcbride, B. A., \& Korth, B. (2011). Are happy children socially successful? Testing a central premise of positive psychology in a sample of preschool children. Journal of Positive Psychology, 6(5), 355-367. https://doi.org/10.1080/17439760.2011.584549. 
Son, D., \& Padilla-Walker, L. M. (2020). Happy helpers: A multidimensional and mixed-method approach to prosocial behavior and its effects on friendship quality, mental health, and wellbeing during adolescence. Journal of Happiness Studies, 21, 1705-1723. https://doi.org/10.1007/ s10902-019-00154-2.

Springer, K. W., \& Hauser, R. M. (2006). An assessment of the construct validity of Ryff's scales of psychological well-being: Method, mode, and measurement effects. Social Science Research, 35(4), 1080-1102. https://doi.org/10.1016/j.ssresearch.2005.07.004.

Steger, M. F. (2016). Hedonia, eudaimonia, and meaning: Me versus us; fleeting versus enduring. In J. Vitters $\varnothing$ (Ed.), Handbook of eudaimonic well-being (pp. 175-182). Springer.

Steinberg, L. (2016). Adolescence (11th ed.). McGraw-Hill.

Tommasi, M., Grassi, P., Balsamo, M., Picconi, L., Furnham, A., \& Saggino, A. (2017). Correlations between personality, affective and filial self-efficacy beliefs, and psychological well-being in a sample of Italian adolescents. Psychological Reports, 121(1), 59-78. https://doi.org/10.1177/00332 94117720698.

Tuerk, C., Anderson, V., Bernier, A., \& Beauchamp, M. H. (2020). Social competence in early childhood: An empirical validation of the SOCIAL model. Journal of Neuropsychology. https://doi.org/ 10.1111/jnp.12230.

Viejo, C., Gómez-López, M., \& Ortega-Ruiz, R. (2018). Adolescents' psychological well-being: A multidimensional measure. International Journal of Environmental Research and Public Health, 15(10), Article 2325. https://doi.org/10.3390/ijerph15102325.

Virtanen, T. E., Vasalampi, K., Torppa, M., Lerkkanen, M.-K., \& Nurmi, J.-E. (2019). Changes in students' psychological well-being during transition from primary school to lower secondary school: A person-centered approach. Learning and Individual Differences, 69, 138-149. https://doi.org/10. 1016/j.lindif.2018.12.001.

Visani, D., Albieri, E., Offidani, E., Ottolini, F., Tomba, E., \& Ruini, C. (2011). Gender differences in psychological well-being and distress during adolescence. In I. Brdar (Ed.), The human pursuit of well-being (pp. 65-70). Springer.

Visani, D., Albieri, E., \& Ruini, C. (2014). School programs for the prevention of mental health problems and the promotion of psychological well-being in children. In G. A. Fava \& C. Ruini (Eds.), Increasing Psychological Well-Being in Clinical and Educational Settings (pp. 177-185). Springer.

Zhang, F., You, Z., Fan, C., Gao, C., Cohen, R., Hsueh, Y., \& Zhou, Z. (2014). Friendship quality, social preference, proximity prestige, and self-perceived social competence: Interactive influences on children's loneliness. Journal of School Psychology, 52(5), 511-526. https://doi.org/10.1016/j.jsp.2014. 06.001 .

Publisher's Note Springer Nature remains neutral with regard to jurisdictional claims in published maps and institutional affiliations. 